\title{
MECHANICAL BEHAVIOUR OF GLASS FIBER REINFORCED EPOXY COMPOSITE MATERIAL
}

\author{
B. GANESHAN \& Dr. S. SURESHKUMAR* \\ Department of Mechanical Engineering, Saveetha School of Engineering, \\ Saveetha Institute of Medical and Technical Sciences, Chennai, Tamil Nadu, India
}

\begin{abstract}
The main objective of this work is to study the three samples of glass fibre reinforced with three different ratio of epoxy resin. In this study the different weight percentage of given material properties are identified by using destructive such as tensile test, impact test, hardness measurement and vibration analysis (non-destructive testing method). The main aim of this study to predict the quality of the materials (weight percentage of suitable given materials) using the above test methods. Testing this sample through tensile, hardness, impact, vibration and comparing it by the testing result to find the best among these three-composite sandwiches which are used to some applications.

KEYWORDS: Composite, Glass Fibre, Epoxy Resin, Destructive Testing \& Vibration
\end{abstract}

Received: May 28, 2018; Accepted: Jun 18, 2019; Published: Jul 16, 2019; Paper Id.: IJMPERDAUG2019110

\section{INTRODUCTION}

The mix of at least two materials is known as the composite material in which material have one of a kind qualities that are totally unique in relation to the individual materials included. The material here weused is glass fibre which consists of numerous extremely fine fibres of glass. Glass fibre has generally similar mechanical properties to different strands, for example, polymers and carbon fibre. In spite of the fact that not as inflexible as carbon fibre, it is a lot less expensive and essentially less weak when utilized in composites. Glass filaments are along these lines utilized as a strengthening specialist for some polymer items; to frame an exceptionally solid and generally lightweight fibre-fortified polymer (FRP) composite material called glass-strengthened plastic (GRP), additionally famously known as "fiberglass". This material contains practically no air or gas, is increasingly thick. epoxy resin is added to each material with different ration. Epoxy has a wide scope of utilizations, including metal coatings, use in hardware/electrical segments/LEDs, high strain electrical covers, paint brush fabricating, fibrefortified plastic materials and auxiliary cements. Epoxy is once in a while utilized as a paste. The territories of utilizations of composite materials have grown quickly and have indeed, even discovered new markets. Composite materials comprise of numerous materials being utilized in refined applications. A composite material produced using at least two constituent materials like fortification (strands, particles, chips, as well as fillers) and grid (polymers, metals, or earthenware production). At least one broken stage is, along these lines, implanted in a consistent stage to frame a composite. The broken stage is generally harder and more grounded than the constant stage and is known as the fortification, though, the consistent stage is named as the framework [1-3]. the composites ought not be viewed basically as a mix of two materials. It unmistakably expresses that; the blend has its own special properties. As far as solidarity to protection from warmth or some other attractive quality, it is 
smarter to achieve properties that the individual segments without anyone else can't accomplish. The composite materials have favourable circumstances over other customary materials because of their higher explicit properties, for example, tractable, flexural and sway qualities, solidness and weakness properties, which empower the basic plan to be progressively adaptable [3-7]. Because of the upsides of composite material, they are broadly utilized in aeronautic trade, mechanical building applications (inside burning motors, warm control, machine parts), electronic bundling, car, and air ship structures and mechanical segments (brakes, drive shafts, tanks, flywheels, and weight vessels), process ventures gear expecting protection from high-temperature erosion, dimensionally stable segments, oxidation, and wear, seaward and inland oil investigation and creation, marine structures, sports, recreation hardware and biomedical gadgets [8-10]. Among all fortifying strands, characteristic filaments have expanded generous significance as fortifications in polymer framework composites. The advantages going with the utilization of normal filaments as support in polymers are their accessibility, biodegradability, low vitality utilization, non-rough nature and ease. Moreover, common filaments have low thickness and high explicit properties. The particular mechanical properties of characteristic strands are identical to those of engineered fortifications. A lot of work has been done to gauge the planned of characteristic filaments as support in polymers. Concentrates on bonds and plastics strengthened with regular filaments, for example, coir, sisal, bamboo, jute, banana and wood strands have been accounted for [11-13]. In fibre fortification polymer composites, the fortifications are either manufactured or normal filaments. Manufactured filaments are produced using orchestrated polymer or little particles [14]. The compound used to make this fibre originate from crude material, for example, oil based synthetic compounds or Petro synthetic substances [15-16]. These materials are polymerized in to a long straight compound that cling to contiguous carbon iotas. Various synthetics compound used to create various kinds of fibre. There are various sorts of engineered strands nylon, polyester, carbon fibre, glass fibre, metallic fibre and so forth. Most engineered strands have great versatility [17-18]. Glass is the most widely recognized fibre utilized in polymer grid composites. Its preferences incorporate its high quality, high concoction opposition, minimal effort and great protecting properties. There are numerous kinds of glass fibre S-glass, E-glass, A-glass and so on yet just two sorts of glass fibres, for example, E-glass and S-glass are most usually utilized as a result of their high elasticity. Glass strands are accessible in various structures like woven textures, consistent and slashed. Because of numerous favourable circumstances, E-glass fibre is taken as fortification in the present research work. Presently a-days, the regular filaments have an incredible consideration as they are a substitute to the debilitating oil sources [19].

\section{MATERIALS AND METHOD}

\section{Materials Used}

Glass fibre was utilized as essential fortification material. Composite examples were manufactured utilizing hand lay-up strategy pursued by pressure. The examples were set up according to ASTM guidelines for testing. Tensile test was executed according to ASTM D638 standard with a test speed of $2 \mathrm{~mm} / \mathrm{min}$. Impact tests were performed by ASTM D256, The materials used in this work for fabrication of composites are given below:

- $\quad$ Resin used: Epoxy resin (Araldite LY556)

- Hardener used: HY917

- $\quad$ Reinforcement: Glass Fibre

- Specimen plate dimension: Unidirectional (UD) glass fibers thickness is $0.2 \mathrm{~mm}$. 


\section{Test Specimen}

For the preparation of the composite we calculate the volume fraction Percentage of glass fibre and epoxy polymer shown in Table1. Specimen preparation2 layers of 1 feet X 1 feet with given composition.

The Glass Fibre/epoxy mixture was prepared by using ultrasonicator at $60^{\circ} \mathrm{C}$ for 3 hours. Next step, the amount of hardener was added to the Glass Fibre/epoxy mixture at room temperature for 20 minutesbefore the infusion of the fibre preform. The Glass Fibre reinforced epoxy composite materials shown in Figure 1.

Table 1: The Weight Percentage of Glass Fibre and Resin Materials

\begin{tabular}{|l|l|l|}
\hline MATERIAL & $\begin{array}{l}\text { GLASSFIBER } \\
\text { (Weight \%) }\end{array}$ & $\begin{array}{l}\text { EPOXY } \\
\text { (Weight \%) }\end{array}$ \\
\hline Sample 1 & 30 & 70 \\
\hline Sample 2 & 20 & 80 \\
\hline Sample 3 & 10 & 90 \\
\hline
\end{tabular}


Figure 1: Composite Specimen

\section{Methodology Steps}

STEP-1: Fabrication using hand lay-up method.

STEP 2:Non-destructive testing.

STEP-3: Destructive testing.

STEP-4: Identification of better sample using the test results

STEP-5: Result analysis

STEP-6: Conclusion

\section{Tensile Test}

A tensile test, otherwise called a tension test, is a standout amongst the most principal and basic kinds of mechanical testing. An elastic test applies pliable (pulling) power to a material and measures the sample's reaction to the pressure. By doing this, ductile tests decide how solid a material is and the amount it can elongate. Tensile tests are normally directed on electromechanical or all-inclusive testing instruments, are easy to perform, and are completely 
institutionalized. This test is conducted under room temperature, according ASTM D638

\section{Impact Test}

A technique for deciding conduct of material exposed to stun stacking in bending, strain, or torsion. The amount typically estimated is the vitality retained in breaking the sample in a solitary blow, as in the Charpy Impact Test, Izod Impact Test, and Tension Impact Test. This test performed under ASTM D256. Impact test set up shown in Figure 2.



Figure 2: Impact Test

\section{Hardness Test}

Hardness measurement is the obstruction of a material to perpetual space. Recognize that hardness is an experimental test and, in this manner, hardness is definitely not a material property. This is on the grounds that there are a few diverse hardness tests that will each decide an alternate hardness esteem for a similar bit of material. In this manner, hardness is test technique reliant and each test outcome must have a mark distinguishing the test strategy used.

\section{Vibration Testing}

Vibration analysis refers to the process of monitoring the vibration signatures specific to a piece of rotating machinery and analysing that information to determine the condition of that equipment. Three types of sensors are commonly used: displacement sensors, velocity sensors and accelerometers. Fundamental accelerometers utilize a piezoelectric precious stone (that changes over sound waves to electrical driving forces and back) connected to a mass that vibrates because of the movement of the part to which the sensor packaging is joined. The test results were determined by acoustic echoes due to vibration. The vibration analysis set up shown in Figure 3.

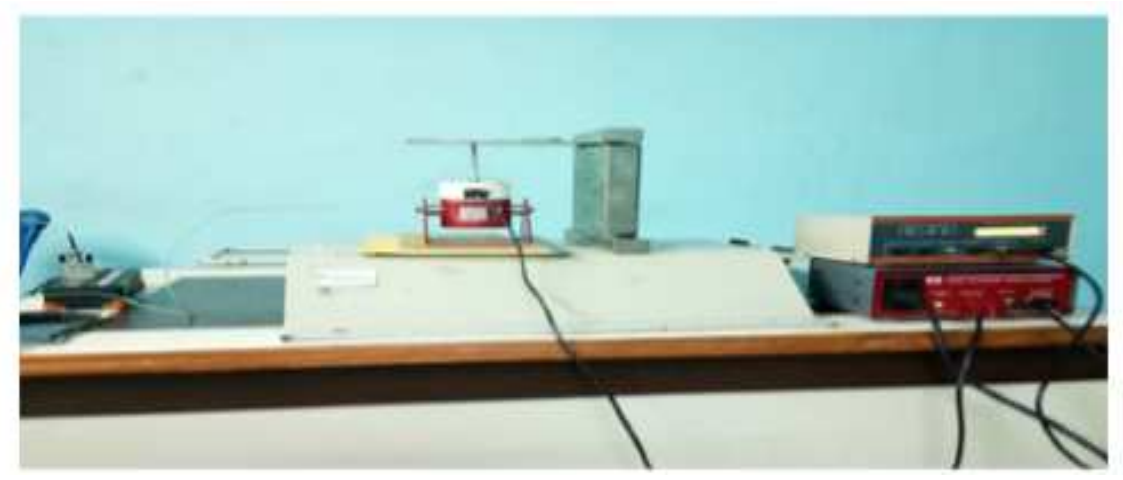

Figure 3: Vibration Analysis Experimental Set Up 


\section{RESULTS AND CONCLUSIONS}

The Present study has been done on three samples made of Glass Fibre reinforced epoxy composite materials. Once the composite samples are formed, the quality of the composite material sample is determined using destructive test methods (tensile test, impact test and hardness survey) and non-destructive testing method (vibration analysis). The results are given below

\section{Tensile Test}

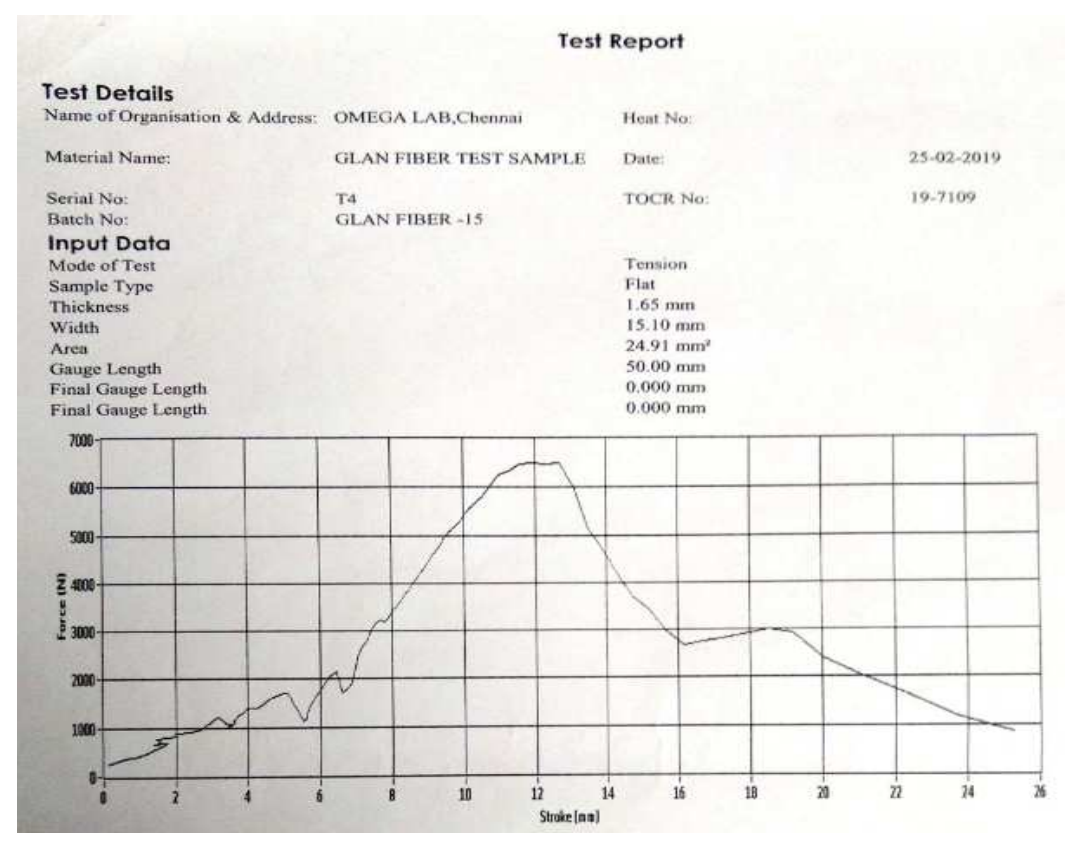

Figure 4: Tensile Test Plot

The Tensile test conducted by under room temperature according ASTM D 638. The plot is between stress and strain. Tensile strength of three samples observed by stress-strain curve. The sample 2 strength is shown in Figure 4, among the three samples, the significantly sample 2 is high tensile strength (650MPa) obtained.

\section{Impact Test}

The Impact test conducted by under room temperature according ASTM D 256. All the three samples tested under the room temperature. Sample 2 is got the high value comparing other two samples. Sample 2 has 2.5 Joules from the Charpy impact test.

\section{Hardness Survey}

Hardness survey conducted under the room temperature based on ASTM D 2583. From the test result it shows that the test sample 2 has the comfortable hardness value comparing other two. Its average hardness value Sample 2 is 21 HN using Barcol hardness method.

\section{Vibration Analysis}

In vibration analysis $376 \mathrm{~Hz}$ frequency probe is used. The quality of composite materials determined by the Vibration analysis method. In this testing method determined adhesive and non-adhesive behaviour of composite material using echo signal.The echo signal flow on the composite material the intensity of echo signal is low, it means that the there 
is good adhesive behaviour between the two material, other hand the intensity of echo signal is high, it means that there is adhesive behaviours is poor between the two materials. In this study the lower level echo signal intensity is observed from the sample 2. It is explained in Figure 5.

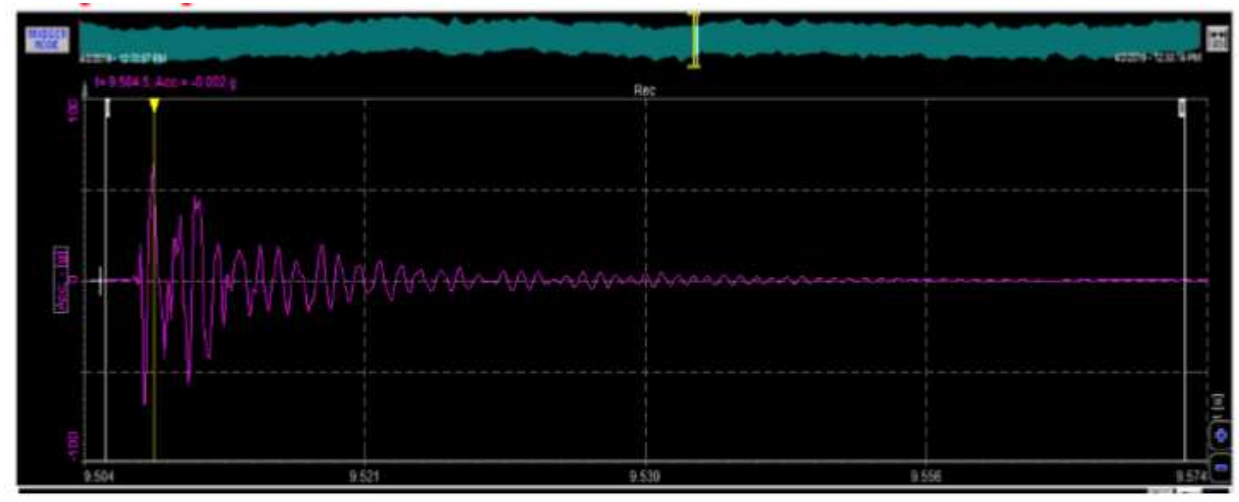

Figure 5: Vibration Analysis Display for Sample 2

\section{CONCLUSIONS}

In this study concluded that the results are follows:

The three sandwich composite samples were made it and sample 2 has good mechanical properties as well as vibration analysis test.

The adhesion of composite materials determined by the vibration analysis test, the sample 2 has good adhesion comparing others.

The tensile strength of sample 2 has $650 \mathrm{MPa}$ is obtained and same sample impact strength value has 2.5 Joules from Charpy impact test.

The hardness value significantly noted in sample 2 is $21 \mathrm{HN}$.

\section{REFERENCES}

1. Verma D., Gope P.C., Shandilya A., Gupta A., Maheshwari M.K., (2013). Coir Fibre Reinforcement and Application in Polymer Composites: A Review, J. Mater. Environ. Sci 4(2), pp. 263-276.

2. Kelly, (1967). A. Sci. American 217 (B), pp.161.

3. Zweben C., (2006). Mechanical Engineers' Handbook, Materials and Mechanical Design 1, pp.380-414.

4. Sahib D.N and Jog, J. P., (1999). Natural Fibre Polymer Composites: A Review, Advances in Polymer Technology, 18(4), pp.351-363.

5. Filho R.D.T., Scrivener K., England G.L., Ghavami K., (2000). Durability of alkali sensitive sisal and coconut fibres in cement mortar composites, Cement Concrete Composites 22, pp. 127-143.

6. Zhong L.X., Fu S.Y., Zhou X.S., Zhan H.Y., (2011). Effect of surface micro fibrillation of sisal fibre on the mechanical properties of sisal/aramid fibre hybrid composites, Composites: Part A 42, pp. 244-252.

7. Acha B.A., Reboredo M.M., Marcovich N.E., (2007). Creep and dynamic mechanical behavior of PP-jute composites: Effect of the interfacial adhesion, Composites: Part A 38, pp. 1507-1516. 
8. Bledzki A.K., Mamun A.A., Volk J., (2010). Barley husk and coconut shell reinforced polypropylene composites: The effect of fibre physical, chemical, and surface properties, Composite Science and technology 70, pp. 840-846.

9. Rozman H.D., Tan K.W., Kumar R.N., Ishak Z.A.M., Ismail H., (2000). The effect of lignin as a Compatibilizer on the physical properties of coconut fibre polypropylene composites, European polymer journal 36, pp.1483-1494.

10. Ronga M.Z., Zhang M.Q., Liu Y., Yang G.C., Zeng H.M., (2001). The effect of fibre treatment on the mechanical properties of unidirectional sisal-reinforced epoxy composites, Composites Science and Technology 61, pp.1437-1447.

11. AsimShahzad, "A study in physical and mechanical properties of hemp fibres", Article ID 325085, Volume 2013.

12. Mizi Fan, "Elementary hemp fibers and strength" Bio Resources 5(4), PP 2307-2322, 2010.

13. A. Shahzad, D.H. Issac and S.M. Alston, "Mechanical Properties of Hemp Fiber Composites".

14. Theresa L. Bayush, BalajiThattai, SelvumPillay and UdayVaidya, "Processing and Characterization of Hemp Fiber Reinforced Polypropylene Composites", ECCM15, 2012.

15. N.P.G. Suardana, YingjunPiao, Jae Kyoo Lim, “Mechanical Properties of Hemp Fibers and Hemp/PP Composites: Effects of Chemical Surface Treatment”, Materials Physics and Mechanics, 2011.

16. Girisha K G, Anil K C\&Akash, "Mechanical Properties of Jute And Hemp Reinforced Epoxy/Polyester Hybrid Composites", International Journal of Research in Engineering \& Technology, Volume 2, Issue 4, PP 245-248, 2014.

17. ShubhashiniOza, Ruoyang Wang \&Dr. Na Lu, "Thermal and Mechanical Properties of Recycled High-Density Polyethylene/hemp Fiber Composites", International Journal of Applied Science and Technology, Volume 1, 2011.

18. Keshavamurthy...et.al, Investigation of tensile properties of fiber reinforced angled ply laminated composites, International journal of emerging technology and advanced engineering.

19. Wang.Y.et.al, properties of composites laminates reinforced with glass multi axial non crimp fabrics $j$ comp.Kullor and Springer G.S.et.al, Mechanics of composite structures, Cambridge university press-stand ford, 2003. 
